\title{
Assessment of the threatened carnivore community in the recently expanded rainforest protected area Anjanaharibe-Sud Special Reserve, Madagascar
}

\author{
Patrick H. Ross ${ }^{1, *}$, Erik Patel ${ }^{2}$, Barry Ferguson ${ }^{3}$, Rojo Nandrianina Ravelijaona ${ }^{4}$, \\ Guy Irenel Raoloniana ${ }^{2}$, Erin Wampole ${ }^{5}$, Brian D. Gerber ${ }^{5}$, Zach J. Farris ${ }^{6}$ \\ ${ }^{1}$ Department of Sustainable Development, Appalachian State University, Living Learning Center, 305 Bodenheimer Drive, \\ Boone, NC 28608, USA \\ ${ }^{2}$ Research and Conservation, Lemur Conservation Foundation, PO Box 249, Myakka City, FL 34251, USA \\ ${ }^{3}$ Independent Researcher, Antalaha (206), SAVA, Madagascar \\ ${ }^{4}$ Department of Biology, University of Antananarivo, Antananarivo 101, Madagascar \\ ${ }^{5}$ Department of Natural Resources Science, University of Rhode Island, Kingston, RI 02881, USA \\ ${ }^{6}$ Department of Health and Exercise Science, Appalachian State University, Leon Levine Hall of Health Sciences, \\ ASU Box 32071, 1179 State Farm Road, Suite 432, Boone, NC 28608, USA
}

\begin{abstract}
Madagascar is an island nation renowned for its biodiversity and species endemism, yet it is still largely understudied despite intense anthropogenic threats including forest loss and edge effects. Anjanaharibe-Sud Special Reserve is a recently expanded rainforest protected area that is lacking detailed surveys and assessments of the native carnivore community of the endemic family Eupleridae. To identify which terrestrial carnivores occupy the reserve and what anthropogenic disturbances and factors best explain their occurrence patterns, we deployed 35 motionactivated cameras to detect native and introduced carnivores. From November 2018 to February 2019, we collected 2918 unique capture events (all species) and confirmed the presence of 5 euplerids: Galidia elegans, Galidictis fasciata, Eupleres goudotii, Fossa fossana, and Cryptoprocta ferox. These results extend the known range of E. goudotii and G. fasciata. In the reserve, F. fossana and G. elegans were the most common and widespread native carnivores, while E. goudotii was the rarest. We highlight the negative impact of edge effects on G. fasciata and F. fossana and the threat posed by the free-ranging non-native carnivore $C$. familiaris. This study represents the first detailed survey and occurrence estimates of the carnivore community of this protected area, allowing comparison with other protected areas in Madagascar. Our empirical findings show that anthropogenic disturbance negatively impacts carnivore existence within the Anjanaharibe-Sud Special Reserve and provide important management recommendations for protecting the carnivore community and the co-occurring wildlife living within this area.
\end{abstract}

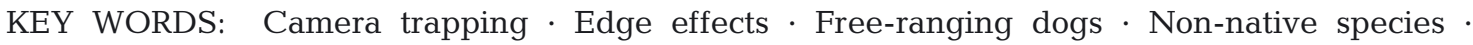
Occupancy

\section{INTRODUCTION}

Tropical rainforests cover only $7 \%$ of the land on Earth yet contain approximately $50 \%$ of global species diversity (Hanley et al. 1995). These biodiverse forests are highly threatened globally, with the

\footnotetext{
${ }^{*}$ Corresponding author: patrickhross@gmail.com
}

United Nations estimating an average net forest loss of 7000000 ha $\mathrm{yr}^{-1}$ between 2000 and 2010 (FAO 2016). Rainforests everywhere face a wide range of anthropogenic threats, including infrastructure and agricultural expansion as well as resource extraction (Geist \& Lambin 2002). These pressures 
result in overall forest loss and confounding threats, such as edge effects. Edge effects are those effects felt by organisms that occur near and are caused by the boundary of 2 or more habitats (Levin 2009). Edge effects can result in microclimate changes that alter and influence population and/or community structures for both flora and fauna occupying the affected area (Lenz et al. 2014). These edge effects have been shown to negatively affect wildlife across multiple taxa throughout the tropics (Koh et al. 2010). While forest loss (and added pressures such as edge effects) occurs globally, it has especially damaging impacts on locations with the densest concentrations of biodiversity (or 'biodiversity hotspots'), many of which lie near the equator (Myers 1988, Brown 2014).

Madagascar, an island nation located off the coast of southeast mainland Africa, is estimated to have one of the densest concentrations of biodiversity globally (Mittermeier et al. 1998). Almost half of Madagascar's forest cover has been lost in the last $60 \mathrm{yr}$; the remaining forest is expected to be lost in the next $80 \mathrm{yr}$ if the annual deforestation rate of 99000 ha $\mathrm{yr}^{-1}(2010-2014)$ continues (Vieilledent et al. 2018, Morelli et al. 2020). The primary threat to Madagascar's forests and its threatened wildlife is land clearing related to 'tavy' (a traditional practice using fire to clear for agriculture), along with timber and/or charcoal production (Vieilledent et al. 2018). In an attempt to protect the nation's threatened biodiversity and endemic species, the Malagasy Government and the Ministry of the Environment and Forests have expanded existing protected areas. Unfortunately, most of Madagascar's protected areas are understudied and lack robust population density estimates and/or diversity assessments of threatened wildlife populations, which limits efforts to manage and conserve these protected areas and the biodiversity they aim to protect (Goodman et al. 2018).

Tropical carnivores are often ecosystem regulators and indicators of environmental health (Miller et al. 2001). These carnivores may also be effective conservation 'umbrella species', as the effective management of their habitat confers protection on numerous other biota in their ecosystems (Noss 1990, Gittleman et al. 2001). The concept of carnivores as umbrella species has been shown to increase species richness, inter-order variability, population viability, and connectivity (Thornton et al. 2016, Figel et al. 2018). Madagascar's endemic carnivores (Family Eupleridae) face numerous anthropogenic pressures, such as habitat loss (Vielledent et al. 2018, Morelli et al. 2020), hunting (Golden 2009, Jenkins et al. 2011), human encroachment, competition with non-native species, and disease transmission (Farris et al. 2015a,b, Rasambainarivo et al. 2017). Recent research on Madagascar's carnivores has highlighted how forest loss, degradation, and human encroachment have negatively influenced carnivores across degraded and edge forest in both single-season and multi-season surveys (Gerber et al. 2012, Farris et al. 2015a, 2017). Data on multiple species of carnivores have demonstrated lower occupancy and/or density in edge habitat near human settlements. These edge and disturbed forest habitats are also associated with increased presence and activity of non-native invasive species, namely free-ranging cats and dogs. Recent research has shown the numerous threats posed to Madagascar's native/endemic carnivores by free-ranging dogs (Canidae Canis familiaris) and cats (Felidae Felis catus) as well as the small Indian civet (Viverridae Viverricula indica). Traits associated with carnivores, including their elusive behavior, often nocturnal activity, large home ranges, and low population densities, have made it particularly difficult to gather reliable estimates. The culmination of these threats and the lack of robust studies have contributed to Madagascar's carnivores being some of the most threatened and least studied carnivores on the planet (Brooke et al. 2014).

To provide more information on this poorly studied, highly threatened group of carnivores, we conducted widespread, non-invasive surveys across a newly expanded protected area to investigate habitat use and factors influencing their distribution. We predicted that various anthropogenic variables such as forest degradation level and distance to human settlement and forest edge will have substantial negative impacts on the native rainforest carnivore occupancy and/or habitat use in the Anjanaharibe-Sud Special Reserve (ASSR) in northeastern Madagascar. To test this hypothesis, our objectives were to (1) survey and document the presence of native and non-native carnivores; (2) calculate and compare site-level trap success (TS, e.g. relative animal activity) of each carnivore as well as co-occurring species; (3) estimate the probability of species occupancy and detection; and (4) evaluate which landscape and habitat features (e.g. distance to edge, distance to village, and forest type) influence their occupancy and detection. To evaluate these predictions, we plotted all camera sites by their GPS coordinate locations in Google Earth Pro (Google). 


\section{MATERIALS AND METHODS}

\subsection{Study area}

We conducted our study in northeastern Madagascar, inside ASSR around the Camp Indri site $\left(14^{\circ} 44^{\prime}\right.$ $29^{\prime \prime} \mathrm{S}, 49^{\circ} 29^{\prime} 50^{\prime \prime} \mathrm{E}$ ) in the SAVA Region (Fig. 1). ASSR lies to the west of the Andapa Basin alongside a chain of igneous mountains with an elevational range from 751-2064 m. Forest types vary from mid-altitude moist evergreen forest to montane ericoid thicket. The ASSR has been governmentally managed under varying authorities since its creation in 1958 and was expanded in size in 2015 from 17194 to 26903 ha. The ASSR is among the wetter of Madagascar's protected areas, receiving approximately $2155 \mathrm{~mm}$ of rainfall annually, mostly between December and April, with average daily temperatures between 14.3 and $22.9^{\circ} \mathrm{C}$.

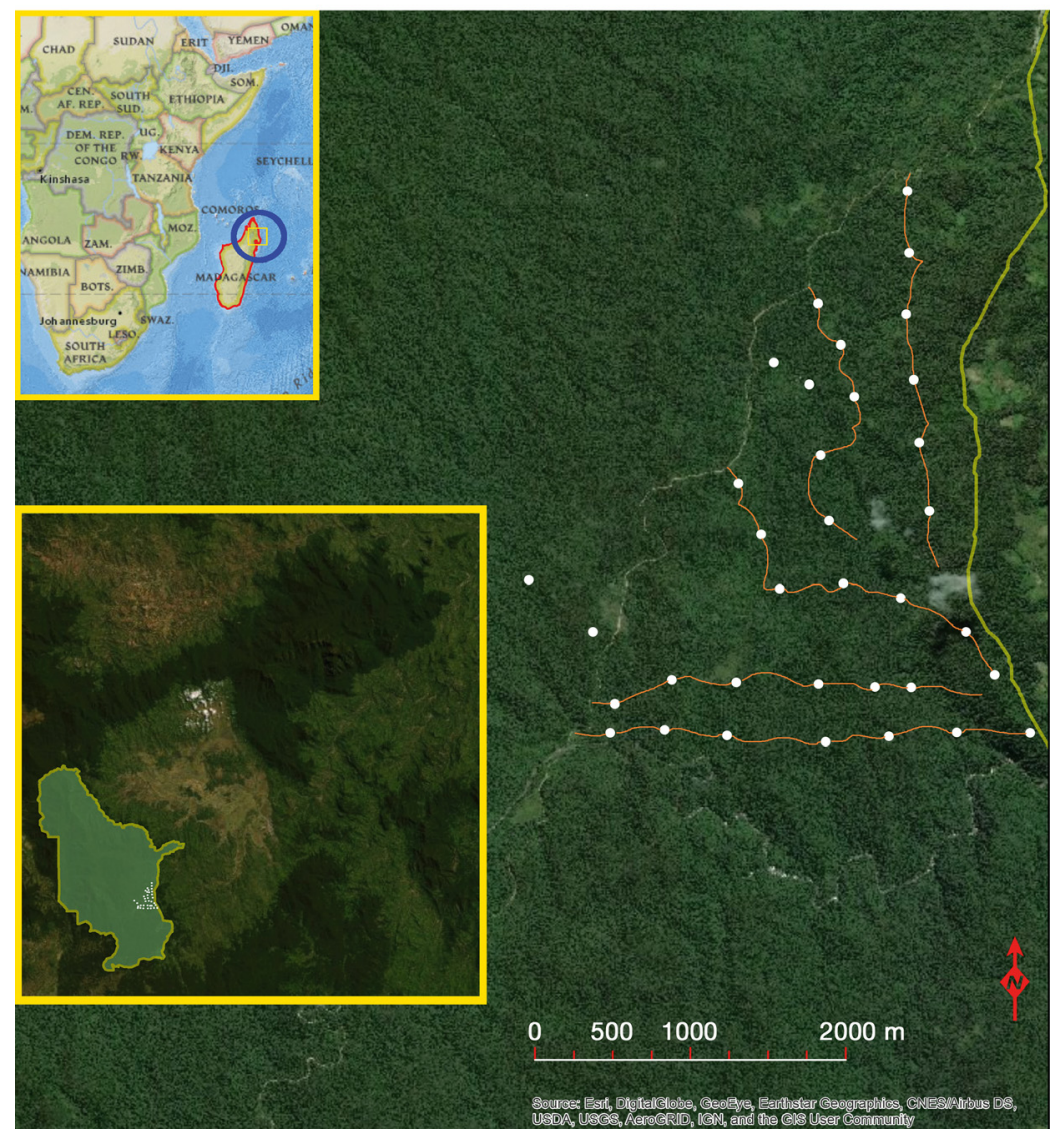

Fig. 1. Study site, including a map of eastern Africa with northern Madagascar and the study site in the north east circled (top left), an outline of the Anjanaharibe-Sud Special Reserve (ASSR) in which our study took place (lower left, light green) with the camera traps (white dots) in the south eastern portion of the park. The main earthen road (light green) that bisects through the ASSR can be seen on the right of the map along with an enlarged view of camera placement (white dots) along transect trails (orange lines)
ASSR is connected to Marojejy National Park, a UNESCO World Heritage Site, through the forest corridor making up the COMATSA-Sud protected area. Taken together, the 'Marojejy National Park Protected Area Complex' is one of the largest and least disturbed rainforest landscapes in Madagascar (Goodman 1998, Goodman et al. 2018).

ASSR's unique microclimate, caused by highly variable elevations, results in high levels of biodiversity. Anecdotal accounts, museum specimens, and opportunistic sightings have documented the presence of 4 native carnivores across the protected forests bordering the Andapa basin (fosa Cryptoprocta ferox, fanaloka Fossa fossana, northern ringtailed vontsira Galidia elegans, and broad striped vontsira Galidictis fasciata) and one non-native carnivore (Vivercula indica) (Goodman et al. 2018). ASSR protects numerous other biota, including 11 species of lemurs, such as the Critically Endangered silky sifaka Propithecus candidus and indri Indri indri. More Nesomyidae rodent species are found here than in any other protected area on the island. There are also 112 bird species and 86 species of reptiles and amphibians; 635 plant species are known to exist in ASSR, of which 6 are not found outside of the reserve (Goodman 1998, Goodman \& Helgen 2010, Goodman et al. 2018). To date, systematic studies of carnivores have not been carried out in the reserve, and reliable occurrence and occupancy estimates of native and nonnative carnivores are lacking. Despite these high levels of biodiversity and unique ecosystems, the unique flora and fauna of ASSR are threatened due to widespread forest loss relating to subsistence agriculture and charcoal production (Vieilledent et al. 2018). Bushmeat hunting, selective logging, and artisanal mining have all been reported within the protected area. Between 1996 and 2016, a total of 404 ha of forests were destroyed in ASSR (Goodman 1998, Goodman et al. 2018). Goodman et al. (2018) noted that quartz extraction in ASSR has resulted in significant forest degradation, and our study confirmed this as our research team observed informal/ illegal mining during our surveys. 


\subsection{Photographic sampling}

We used camera traps to sample terrestrial wildlife in southeastern ASSR from 8 November 2018 to 27 February 2019. Camera models included Moultrie M888, M880, D55, and A35 (Moultrie Feeders), WGI Terra Extreme (WildGame Innovations), Bushnell Trophy Cam HD (Bushnell), HCO-SG565 (HCO ScoutGuard), and Stealth Cam ZX3 (Stealth Cam). We placed cameras on 5 existing transects and 2 small newly cut trails, covering a total survey length of $13.97 \mathrm{~km}$. Camera trap elevation ranged from 845-1057 m above sea level. The cameras were placed an average $( \pm$ SD) of $340.6 \pm 73.62 \mathrm{~m}$ apart. This distance is at or below the estimated home range for 5 of Madagascar's rainforest carnivores (excluding $C$. ferox which has a home range $>500 \mathrm{~m}$ ) (Goodman 2012). We placed cameras approximately 10-20 cm off the ground. No baits or lures were used. Camera sites included degraded, edge forest near roads or villages ( $<500 \mathrm{~m}$ from edge; $\mathrm{n}=21$ ) and nondegraded forest $(>500 \mathrm{~m}$ from edge; $\mathrm{n}=14)$. We chose these camera site locations based on the presence of extensive existing transects as well as varying levels of forest degradation and distance to multiple anthropogenic pressures. All cameras were set to high sensitivity and to record 3 consecutive photographs for each independent trigger. We recorded the location of each camera (UTM) and elevation using 2 handheld Garmin Etrex GPS units. After the initial setup, we checked the cameras at approximately $6,14,20$, and $30 \mathrm{~d}$ post-setup and then every $30 \mathrm{~d}$ for the next 3 mo.

\subsection{Landscape covariates}

Past research on Madagascar's carnivores has shown that there are negative effects related to forest type (contiguous vs. degraded), distance to edge, distance to village, and non-native carnivores (Gerber et al. 2012, Farris et al. 2017). We investigated how these variables influence native carnivore occupancy and detection at ASSR. We expected to find lower occupancy (habitat use) and activity (TS) in degraded, edge forest sites near human settlements for all native carnivores, but higher occupancy and activity for non-native carnivores. For each camera station, we recorded elevation and measured the distance from camera trap placements to villages, cultivated areas, forest edge, and housing structures. We defined a village as any location with 10 or more housing structures. We defined a housing structure as any single structural dwelling, standing $\geq 200 \mathrm{~m}$ from a village that could be seen on the satellite imagery. We defined cultivated area as any location of cleared forest where we could confirm agricultural products, such as rice, pineapple, sugar cane, cloves, etc., were being grown. We defined forest edge as any location where there was a clear change from having canopy cover to no canopy cover (i.e. a hard edge between forest and non-forest areas). We classified forest type as either non-degraded (i.e. high canopy cover with limited presence of non-native flora species present) or degraded, edge (i.e. sparse canopy cover with evidence of damage from fire or cutting and with non-native species of flora). To evaluate the correlation among our hypothesized covariates, we performed a correlation analysis that showed that distance to cultivated area, distance to housing structure, and elevation were highly correlated ( $r>0.75$ ) with other variables. As a result, we used distance to village $(\mathrm{m})$, distance to edge $(\mathrm{m})$, and forest type as covariates in our models; however, we recognize that some of these variables are correlated with the variables mentioned above (e.g. cultivated area and housing structure), and our interpretation provided in the discussion may also be influenced by these variables that we removed from our models.

\subsection{Data analysis}

We defined a capture event as all photographs of a given species at a camera station within a $30 \mathrm{~min}$ period (Di Bitetti et al. 2006). We used this time period to ensure temporal independence among captures. Using the capture events across all camera stations, we constructed a capture history for each species where 0 indicates non-detection and 1 indicates detection for each $24 \mathrm{~h}$ period. We defined a trap night as a $24 \mathrm{~h}$ period in which one camera was functioning properly with no malfunctions. We then totaled all trap nights for all camera stations across the entire sampling grid. For each species, we calculated TS as the total number of captures divided by total trap nights multiplied by 100 . We calculated this measure of relative activity for all native and nonnative carnivores, birds, and small mammals to compare their activity and presence across the entire surveyed landscape.

To evaluate species occurrence while accounting for imperfect detection, we used single-season, singlespecies occupancy modeling implemented in the 'unmarked' package in R v.3.6 (MacKenzie et al. 
2002, Fiske \& Chandler 2011, R Core Team 2014). Given the limited spatial scale of the camera trap grid $\left(12.69 \mathrm{~km}^{2}\right)$, the movement of animals in and out of the camera area, and the limited habitat sampling (non-degraded vs. degraded), we consider occupancy estimates to be a measure of habitat use rather than estimates of true occupancy. We modeled species occupancy $(\psi)$ and detection probability (p) for all native and non-native carnivores having sufficient captures for model convergence (this excluded E. goudotii). We assumed that occupancy did not change during the survey period and that detection of each species at each location was independent. To evaluate how both occupancy and detection might change during the survey period or across the landscape, we included the aforementioned variables as covariates on both occupancy and detection. We did not consider multiple variables on the same parameter due to sample size. We established a priori models before modeling occurred and modeled detection first before moving on to occupancy. We removed any model that did not have proper convergence (e.g. failed to produce estimate or had high error values associated with parameter). We evaluated all models using Akaike's information criterion corrected for small sample sizes $\left(\mathrm{AIC}_{\mathrm{C}}\right)$ and report all top-ranking models $\left(\Delta \mathrm{AIC}_{\mathrm{C}}<2.0\right)$ (Burnham \& Anderson 2002).

\section{RESULTS}

From November 2018 to February 2019, we sampled across 3270 trap nights and collected 2918 unique photographic capture events, including 760 captures of native terrestrial carnivores and 227 captures of non-native terrestrial carnivores (Table 1). We observed 5 endemic carnivore species (Galidia elegans, Galidictis fasciata, Eupleres goudotii, Fossa fossana, and Cryptoprocta ferox) and only one non- native carnivore (free-ranging dog Canis familiaris). We did not observe the native Salanoia concolor or the non-native carnivores Felis catus and Viverricula indica. $V$. indica was seen in the original surveys by Goodman (1998) near the village of Ranomafana and once at night near the village of Marolakana, which has since been abandoned (S. Goodman pers. comm.). The most common native carnivore was $F$. fossana with 157 captures across 27 sites and a TS estimate $( \pm \mathrm{SE})$ of $4.70 \pm 1.20$ (Fig. 2), followed by $G$. fasciata with 32 captures at 14 sites (TS $=0.86 \pm 0.33$; Table 1). The rarest native carnivore was E. goudotii, with 2 captures across 2 sites (TS $=0.06 \pm 0.04$; Fig. 2). The non-native $C$. familiaris had 72 captures at 21 sites $(\mathrm{TS}=2.20 \pm 0.55$; Table 1$)$.

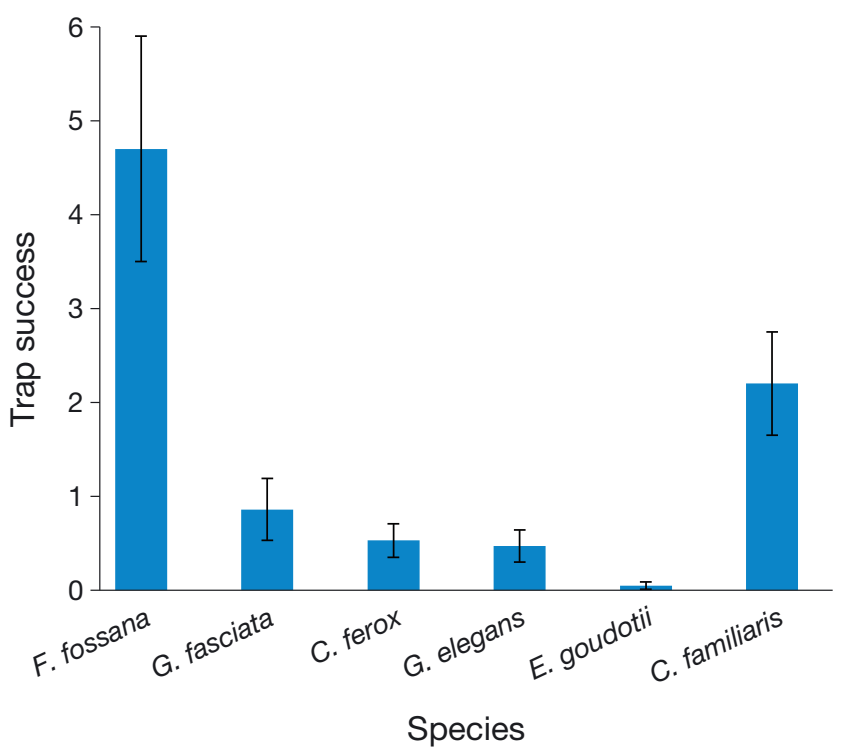

Fig. 2. Carnivore trap success $( \pm \mathrm{SE})$ within the Anjanaharibe-Sud Special Reserve. Trap success is the number of independent photographic capture events of a species divided by the number of trap nights, multiplied by 100 . Species shown are Fossa fossana, Galidictis fasciata, Cryptoprocta ferox, Galidia elegans, Eupleres goudotii, and Canis familiaris

Table 1. Carnivores identified in our survey of the Anjanaharibe-Sud Special Reserve (ASSR), including IUCN classification (VU: Vulnerable; LC: Least Concern), activity pattern, body size, quantity of unique capture events, number of camera stations in which they appeared (out of 35), and trap success (TS) with standard error. TS was calculated as number of captures divided by total trap nights (3270) multiplied by 100. Bold font represents non-native species

\begin{tabular}{|lcccccr|}
\hline Species & IUCN status & Activity & Weight $(\mathrm{kg})$ & No. of captures & No. of stations & TS $( \pm$ SE) \\
\hline Fossa fossana & VU & Nocturnal & 1.7 & 157 & 28 & $4.7( \pm 1.2)$ \\
Galidictis fasciata & VU & Nocturnal & $<1$ & 31 & 15 & $0.86( \pm 0.33)$ \\
Cryptoprocta ferox & VU & Crepuscular & 7 & 17 & 12 & $0.53( \pm 0.18)$ \\
Galidia elegans & LC & Diurnal & $<1$ & 2 & 11 & $0.47( \pm 0.17)$ \\
Eupleres goudotii & VU & Nocturnal & 1.5 & 72 & 2 & $0.05( \pm 0.04)$ \\
Canis familiaris & LC & Crepuscular & 30 & & 20 & $2.201( \pm 0.55)$ \\
\hline
\end{tabular}


Occupancy modeling revealed that the native carnivores $F$. fossana and $G$. elegans had the most widespread distribution, with an average occupancy estimated at $\psi=0.80$ for both $F$. fossana $( \pm 0.09 \mathrm{SE})$ and $G$. elegans ( $\pm 0.35 \mathrm{SE})$. F. fossana occupancy was best explained by distance to edge $(\beta=$ $0.94 \pm 0.60 ; p=0.12$ ) with probability of occupancy being at or near 1.0 at locations occurring $>500 \mathrm{~m}$ from the forest edge (Fig. 3). G. fasciata occupancy $(\psi=0.52 \pm 0.13$; Table 2$)$ also was best explained by distance to edge $(\beta=1.01$ $\pm 0.52 ; \mathrm{p}=0.05$ ) with the native carnivore having a strong increase in occupancy $>500 \mathrm{~m}$ from forest edge (Fig. 4). C. ferox $(\psi=0.65 \pm 0.23), G$. elegans $(\psi=0.80 \pm 0.35)$, and the nonnative $C$. familiaris $(\psi=0.70 \pm 0.13$ ) oc-

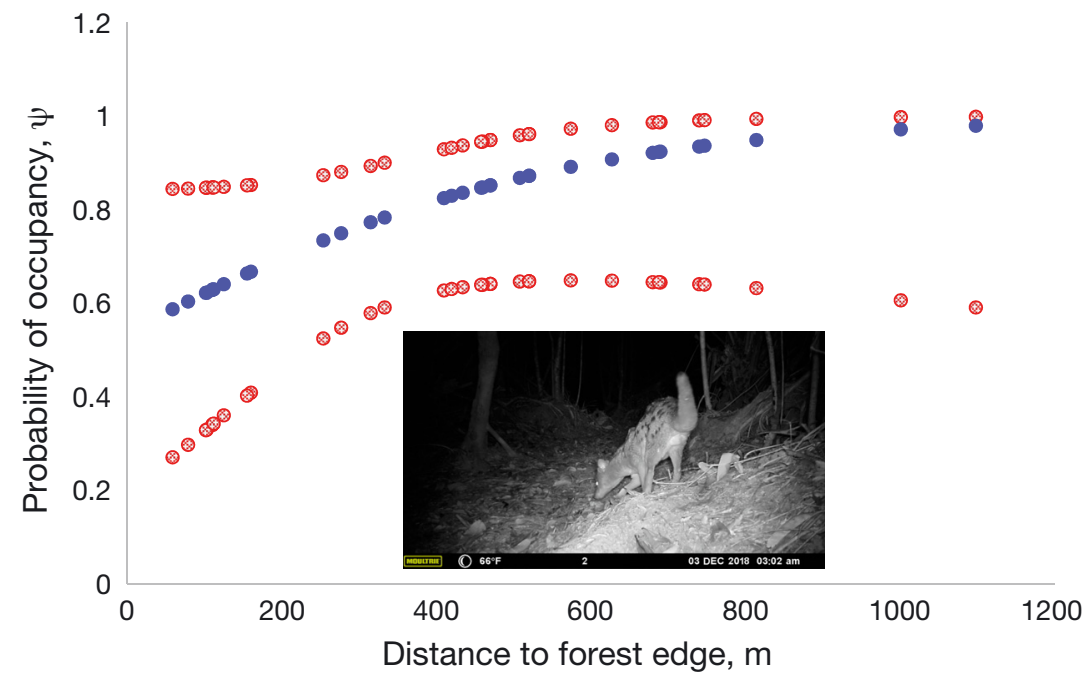

Fig. 3. Probability of occupancy for Fossa fossana versus distance to forest edge across the Anjanaharibe-Sud Special Reserve. Sampling of carnivores occurred from November 2018 to February 2019. Solid blue points: our estimation; hollow red points: SE cupancy was constant across the landscape (Table 2). Forest type was the most common variable explaining probability of detection for F. fossana, G. elegans, and C. familiaris (Table 2). Detection of F. fossana $(\beta=0.64 \pm 0.30 ; \mathrm{p}=0.03)$ and $C$. familiaris $(\beta=-1.73 \pm 0.78 ; p=0.02)$ was influenced by degraded forest. All other carnivores had a constant probability of detection across the landscape.

\section{DISCUSSION}

We surveyed across ASSR and tested the effect of anthropogenic pressures, namely forest edge, on threatened carnivores and found that multiple native carnivores are impacted by anthropogenic variables and show a sensitivity and avoidance of

Table 2. Top-ranking occupancy models for Cryptoprocta ferox, Fossa fossana, Galidictis fasciata, Galidia elegans, and Canis familiaris, including Akaike's information criterion (AIC) value, AIC weight (wt.), number of parameters $(K)$, and averaged estimates of occupancy $(\psi)$ and detection (p) for 5 native carnivores and 1 non-native carnivore resulting from static (singleseason, single-species) occupancy estimation determined through photographic surveys of rainforest in the Anjanaharibe-Sud

Special Reserve. Bold represents non-native species

\begin{tabular}{|c|c|c|c|c|c|c|c|}
\hline Species & Model & AIC & AIC wt. & $\Delta \mathrm{AIC}$ & $K$ & $\psi(\mathrm{SE})$ & $\mathrm{p}(\mathrm{SE})$ \\
\hline \multirow[t]{6}{*}{ C. ferox } & $\psi(),. \mathrm{p}()$. & 160.01 & 0.23 & 0 & 2 & \multirow[t]{6}{*}{$0.65(0.23)$} & \multirow[t]{6}{*}{$0.04(0.02)$} \\
\hline & $\psi($ edge $), \mathrm{p}()$. & 161.16 & 0.13 & 1.16 & 3 & & \\
\hline & $\psi($ structure), $\mathrm{p}()$. & 161.22 & 0.12 & 1.21 & 3 & & \\
\hline & $\psi(),. \mathrm{p}$ (forest) & 161.92 & 0.09 & 1.91 & 3 & & \\
\hline & $\psi$ (forest), $\mathrm{p}()$. & 161.95 & 0.09 & 1.94 & 3 & & \\
\hline & $\psi(),. \mathrm{p}$ (edge) & 162 & 0.08 & 1.99 & 3 & & \\
\hline \multirow[t]{3}{*}{ F. fossana } & $\psi($ edge), p (forest) & 597.63 & 0.3 & 0 & 4 & \multirow[t]{3}{*}{$0.80(0.09)$} & \multirow[t]{3}{*}{$0.24(0.03)$} \\
\hline & $\psi(),. \mathrm{p}$ (forest) & 598.88 & 0.16 & 1.24 & 3 & & \\
\hline & $\psi$ (forest), p (forest) & 599.62 & 0.11 & 1.98 & 4 & & \\
\hline \multirow[t]{3}{*}{ G. fasciata } & $\psi($ edge), $\mathrm{p}()$. & 234.63 & 0.3 & 0 & 3 & \multirow[t]{3}{*}{$0.52(0.13)$} & \multirow[t]{3}{*}{$0.10(0.03)$} \\
\hline & $\psi($ edge), p (edge) & 234.69 & 0.29 & 0.06 & 4 & & \\
\hline & $\psi$ (edge), $\mathrm{p}$ (forest) & 235.95 & 0.16 & 1.32 & 4 & & \\
\hline \multirow[t]{2}{*}{ G. elegans } & $\psi(),. \mathrm{p}$ (forest) & 150.68 & 0.32 & 0 & 3 & \multirow[t]{2}{*}{$0.80(0.35)$} & \multirow[t]{2}{*}{$0.03(0.02)$} \\
\hline & $\psi($ edge), p (edge) & 151.89 & 0.17 & 1.2 & 4 & & \\
\hline \multirow[t]{4}{*}{ C. familiaris } & $\psi(),. \mathrm{p}$ (forest) & 365.92 & 0.31 & 0 & 3 & \multirow[t]{4}{*}{$0.70(0.13)$} & \multirow[t]{4}{*}{$0.09(0.03)$} \\
\hline & $\psi($ structure), $\mathrm{p}$ (forest) & 267.26 & 0.16 & 1.34 & 4 & & \\
\hline & $\psi($ edge), $\mathrm{p}$ (forest) & 367.31 & 0.16 & 1.39 & 4 & & \\
\hline & $\psi$ (forest), $\mathrm{p}$ (forest) & 367.48 & 0.14 & 1.55 & 4 & & \\
\hline
\end{tabular}




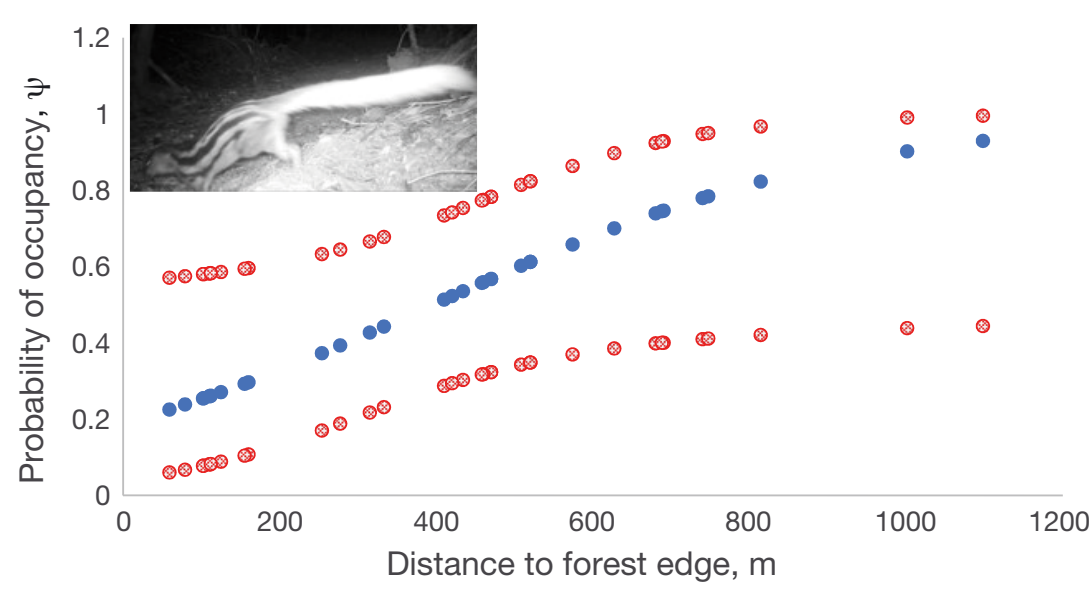

Fig. 4. Probability of occupancy for Galidictis fasciata versus distance to forest edge across the Anjanaharibe-Sud Special Reserve. Sampling of carnivores occurred from November 2018 to February 2019. Solid blue points: our estimation; hollow red points: SE

forest edge habitat, as has also been demonstrated in other studies across Madagascar (Gerber et al. 2012, Farris et al. 2015a,b). Of the anthropogenic variables that we measured in ASSR, distance to forest edge and difference in forest degradation level had the most measurable impact on the carnivores. We observed the presence of 5 out of Madagascar's 6 carnivores known to occupy the northeastern region (Goodman 2012, Farris 2014), failing only to capture Salanoia concolor. This poorly studied carnivore has perhaps the most limited geographical range of any native carnivore in Madagascar (Goodman 2012) and appears to not exist further north than Makira Natural Park. Our findings concur with other published work on Madagascar's carnivores by highlighting the widespread distribution and occupancy of some carnivores (Fossa fossana and Galidia elegans) and the overall rarity of others (Eupleres goudotii) (Goodman 2012). These findings, that forest edge and pressures associated with edge (i.e. invasive species) impact the native carnivores, concur with other surveys/studies across Madagascar's eastern rainforest region and highlight the need for large, contiguous protected areas such as the ASSR, COMATSA-Sud and Marojejy National Park that provide a buffer against the human onslaught on native and endemic species. However, additional multi-year surveys and more widespread surveys of carnivores and their habitat are needed to monitor changes and responses to on-going anthropogenic disturbance across this protected area complex.

\subsection{Individual species overview}

F. fossana, classified by the IUCN as Vulnerable (IUCN 2020), had the highest activity (i.e. TS) and was the most widespread native carnivore in our study. These findings were similar to estimates from Masoala-Makira $(\psi=0.70$; Farris et al. 2015a,b), and Ranomafana $(\psi=0.98$; Gerber et al. 2012), where F. fossana were shown to be sensitive to habitat degradation and to multiple non-native species (Farris et al. 2016). Our study demonstrated that $F$. fossana has a sensitivity to edge habitat and a strong preference for contiguous habitat located $1000 \mathrm{~m}$ or further from forest edge, which concurs with findings from other areas across eastern Madagascar (Gerber 2010, Goodman 2012). We suggest that the high occupancy of $F$. fossana within our study area at the ASSR is likely due to the absence of nonnative carnivores (namely free-ranging cats Felis catus and Viverricula indica) in the surveyed area and the amount of intact, non-degraded rainforest habitat type. These factors may result in higher numbers of potential prey species (birds and small mammals) across the ASSR, thus resulting in more widespread distribution of $F$. fossana and other cooccurring carnivores.

In our survey, G. elegans, classified by the IUCN as Least Concern (IUCN 2020), had the same probability of occupancy as F. fossana, revealing that the species is widely distributed and common across the ASSR landscape. Surveys across other protected areas have shown $G$. elegans to have wide-ranging occupancy estimates, including $\psi=0.48$ at MasoalaMakira (Farris et al. 2015b), $\psi=0.62 \pm 0.12$ at Betampona (Rasambainarivo et al. 2017), and $\psi=1.0$ at Ranomafana National Park (Gerber et al. 2012). This native carnivore demonstrates highly plastic, generalist behavior (Goodman 2012) and is known to occupy both degraded/fragmented and contiguous forests (Gerber et al. 2012, Farris et al. 2015a, Kotschwar-Logan et al. 2015). These traits likely help explain the wide-spread distribution of G. elegans across the ASSR, given that our study took place in established transects and sampled across areas near forest edge and near a highly active established trail. Finally, Beaudrot et al. (2018) showed that G. elegans at Ranomafana moved from areas at higher elevations to locations less than $1000 \mathrm{~m}$ above sea level 
over a 6 yr period. At the ASSR, 33 out of our 35 camera stations were above $900 \mathrm{~m}$ in elevation, and this higher elevation across the ASSR protected area may influence their distribution and/or use of various habitat types and may contribute to the long-term protection of this threatened carnivore.

Our survey extended the known range of Galidictis fasciata. G. fasciata is classified as Vulnerable (IUCN 2020), and its range extended in 2012 into MasoalaMakira (Farris 2014). This carnivore has consistently been shown to be one of the rarest of Madagascar's native carnivore community. Estimates from other protected areas, including Masoala-Makira and Ranomafana, revealed a more limited distribution. However, the Betampona Reserve (Rasambainarivo et al. 2017) showed occupancy estimated at $\psi=0.80$. We showed that forest edge negatively influences $G$. fasciata occupancy at the ASSR, and this relationship with edge may be associated with other anthropogenic variables not included in our modeling (e.g. human activity, non-native species, micro-habitat features). The absence of $V$. indica and $F$. catus within the study area is a positive, as both species have been shown to negatively influence $G$. fasciata at Masoala-Makira and may also contribute to their more widespread distribution across the protected area. Additionally, the absence of the similarly sized sympatric $S$. concolor, which is estimated to have a diet similar to $V$. indica and F. catus (Albignac 1972) and overlaps spatially with $G$. fasciata across multiple protected areas, may also play a role in their increased occupancy at the ASSR. Finally, poaching remains little studied across Madagascar but is widespread and has influenced populations of multiple native carnivores at locations like Masoala-Makira, and Ranomafana (Golden 2009, Kotschwar-Logan et al. 2015, Borgerson, 2016). The ASSR is known to experience less disturbance than neighboring Marojey National Park because of a smaller human population (E. Patel unpubl. data), and thus could be a reason we see higher occupancy estimates of G. fasciata and co-occurring native carnivores in the ASSR compared other protected areas.

Cryptoprocta ferox, classified as Vulnerable (IUCN 2020), is the largest and perhaps most studied of Madagascar's carnivores. Estimates from the ASSR were comparable to Masoala-Makira $(\psi=0.68$; Farris et al. 2015b), Betampona ( $\psi=0.95$; Rasambainarivo et al. 2017) and Ranomafana ( $\psi=0.93$; Gerber et al. 2012). The lower occupancy in the ASSR may be related to factors such as their large home range, as the species is known to traverse large areas of intact forests (Gerber et al. 2012) and is not limited to just forested areas (Hawkins 1998, Hawkins \& Racey 2005). Canis familiaris has been shown to negatively influence the temporal and spatial patterns of $C$. ferox at multiple sites in Madagascar (Farris et al. 2016, 2017, 2020, Merson 2017), and the lower occupancy and TS estimates at ASSR may be the result of the widespread distribution and activity of C. familiaris across the surveyed area. C. ferox populations have been shown to be decreasing across Ranomafana National Park over a 6 yr period, and these trends appear to be linked to $C$. familiaris as well. Additional research on C. ferox populations, particularly how they are changing over time, is needed across all of Madagascar.

Eupleres goudotii (falanouc), which is classified as Vulnerable (IUCN 2020), was the rarest carnivore in our study with only 2 captures, thus preventing us from estimating their occupancy. However, this carnivore had never been documented in the ASSR before. Its recent discovery in the protected area can be attributed to the modern technology used to find it (motion-sensing cameras) and the fact that the species is a primarily nocturnal carnivore (Goodman \& Helgen 2010, Farris et al. 2015a). E. goudotii is believed to show a preference for intact, non-degraded forest; however, they have been shown to exist in degraded forests in other protected areas (Farris et al. 2015b). E. goudotii has a relatively low site-level occurrence across the Masoala-Makira protected area at $(\psi=0.31$; Farris et al. 2015b), Ranomafana $(\psi=0.07$; Gerber et al. 2012), and Betampona $(\psi=0.03$; Rasambainarivo et al. 2017). However, early results from Mantadia National Park show that E. goudotii is the most widespread and active carnivore in the protected area (E. Wampole pers. comm.). Elevation may be an additional factor contributing to low occupancy of E. goudotii across the ASSR, as Goodman (2012) showed E. goudotii to commonly occur between 50 and $600 \mathrm{~m}$ above sea level (the lowest ASSR camera station was $845 \mathrm{~m}$ above sea level). Distance from village may also influence E. goudotii populations, as surveys of local people near Ranomafana revealed that E. goudotii occupied forest habitat an average of $6.3 \mathrm{~km}$ away from community centers - almost triple the distance from the nearest village to cameras in the ASSR (Kotschwar-Logan et al. 2015).

\subsection{Native vs. non-native species}

In addition to our findings on native carnivores, we also confirmed the presence and documented the widespread distribution of non-native, free-ranging 
C. familiaris within the study area. This non-native species is broadly distributed across the landscape and represents a threat to the native fauna given their ability to transmit disease (Rasambainarivo et al. 2017, 2018), negatively influence bird and small mammal populations (Murphy et al. 2017, 2018), and alter the spatial (Farris et al. 2016, 2017, 2020) and temporal (Gerber et al. 2012, Farris et al. 2015a) activity of native carnivores. Research from these other protected areas across Madagascar has revealed similar negative effects from non-native $V$. indica and $F$. catus. However, as mentioned above, these 2 nonnative predators were not captured at the ASSR during our surveys. While they may be present and active at sites not surveyed during this study, the absence of these 2 predators within our study site may be contributing to the high occupancy estimates for multiple native carnivores estimated for this study. An effective management approach which reduces $C$. familiaris populations and prevents the introduction and/or spread of $V$. indica and $F$. catus across the ASSR is needed to mitigate current damage and prevent future biodiversity loss. Other protected areas in Madagascar (Ranomafana, Andasibe-Mantadia; Z. J. Farris unpubl. data), have been host to spay/neuter and vaccination programs designed to halt similar pressures. Additionally, education programs targeted at informing owners about the negative impacts of pets on wildlife and how to minimize wildlife interactions by avoiding specific forest locations and/or times of the day would potentially reduce biodiversity loss.

\subsection{Protection and management of the ASSR}

The findings of this study highlight the threat posed to native carnivores by forest loss within the ASSR. In particular, the negative effects of edge and severely degraded forest on native carnivores requires targeted management that addresses further forest loss around the perimeter of the ASSR. Specifically, we showed that $F$. fossana and $G$. fasciata are negatively affected by forest edge. Additional studies of how edge effects impact the activity of these carnivores, their prey, and the available habitat need to be conducted to effectively manage these species. Further, we argue that the increase in number and distribution of free-ranging $C$. familiaris warrants efforts to mitigate this threat to the native fauna and flora of the ASSR. Effective management of the ASSR will not only result in the protection of these carnivores but will also safeguard the numerous, diverse wildlife that occupy the reserve. Since the protection of many of these carnivores is based on large interconnected contiguous sections of forest, they ultimately act as umbrella species, whose protection also shields other wildlife species who fall within their ranges.

Acknowledgements. We thank the government of the Democratic Republic of Madagascar and Madagascar National Parks for permission to conduct research in AnjanaharibeSud Special Reserve. For logistical support, thanks are due to ICTE / MICET and the Lemur Conservation Foundation. This study was supported by the Lemur Conservation Foundation, US Department of State's Benjamin A Gilman scholarship and the School for International Training. We are thankful for the insight and comments that editors and reviewers offered to improve the final version.

\section{LITERATURE CITED}

Albignac R (1972) The Carnivora of Madagascar. In: Battistini R, Richard-Vindard G (eds) Biogeography and ecology in Madagascar. Dr. W Junk Publishers, The Hague, p 667-682

* Beaudrot L, Acevedo M, Lessard JP, Sheil D, Larney E, Wright P, Ahumada J (2018) Distributional shifts in a biodiversity hotspot. Biol Conserv 228:252-258

* Borgerson C (2016) Optimizing conservation policy: the importance of seasonal variation in hunting and meat consumption on the Masoala Peninsula of Madagascar. Oryx 50:405-418

Brooke ZM, Bielby J, Nambiar K, Carbone C (2014) Correlates of research effort in carnivores: body size, range size and diet matter. PLOS ONE 9:e93195

* Brown JH (2014) Why are there so many species in the tropics? J Biogeogr 41:8-22

Burnham KP, Anderson DR (2002) Model selection and multimodel inference: a practical information-theoretic approach. Springer, Berlin

* Di Bitetti MS, Paviolo A, De Angelo C (2006) Density, habitat use and activity patterns of ocelots (Leopardus pardalis) in the Atlantic Forest of Misiones, Argentina. J Zool 270: 153-163

FAO (2016) Forests and agriculture: land-use challenges and opportunities. State of the World's Forests 2016. FAO, Rome

Farris ZJ (2014) Response of Madagascar's endemic carnivores to fragmentation, hunting, and exotic carnivores across the Masosala-Makira landscape. PhD thesis, Virginia Polytechnic Institute and State University, Blacksburg, VA

Farris ZJ, Gerber BD, Karpanty S, Murphy A, Andrianjakarivelo V, Ratelolahy F, Kelly MJ (2015a) When carnivores roam: temporal patterns and overlap among Madagascar's native and exotic carnivores. J Zool 296:45-57

Farris ZJ, Golden CD, Karpanty S, Murphy A and others (2015b) Hunting, exotic carnivores, and habitat loss: anthropogenic effects on a native carnivore community, Madagascar. PLOS ONE 10:e0136456

Farris ZJ, Kelly MJ, Karpanty S, Ratelolahy F (2016) Patterns of spatial co-occurrence among native and exotic carnivores in north-eastern Madagascar. Anim Conserv 19: 189-198

Farris ZJ, Gerber BD, Valenta K, Rafaliarison R and others (2017) Threats to a rainforest carnivore community: a 
multi-year assessment of occupancy and co-occurrence in Madagascar. Biol Conserv 210:116-124

Farris ZJ, Gerber BD, Karpanty S, Murphy A, Wampole E, Ratelolahy F, Kelly MJ (2020) Exploring and interpreting spatiotemporal interactions between native and invasive carnivores across a gradient of rainforest degradation. Biol Invasions 22:2033-2047

Figel JJ, Castañeda F, Calderón AP, de la Torre JA, GarcíaPadilla E, Noss RF (2018) Threatened amphibians sheltered under the big cat's umbrella: conservation of jaguars Panthera onca (Carnivora: Felidae) and endemic herpetofauna in Central America. Rev Biol Trop 66:1741-1753

Fiske I, Chandler R (2011) unmarked: an R package for fitting hierarchical models of wildlife occurrence and abundance. J Stat Softw 43:1-23

Geist HJ, Lambin EF (2002) Proximate causes and underlying driving forces of tropical deforestation. Bioscience 52:143-150

Gerber BD (2010) Comparing density analyses and carnivore ecology in Madagascar's southeastern rainforest. MSc thesis, Virginia Polytechnic Institute and State University, Blacksburg, VA

* Gerber BD, Karpanty SM, Randrianantenaina J (2012) The impact of forest logging and fragmentation on carnivore species composition, density and occupancy in Madagascar's rainforests. Oryx 46:414-422

Gittleman JL, Funk SM, MacDonald DW, Wayne RK (eds) (2001) Carnivore conservation. Cambridge University Press, Cambridge

Golden CD (2009) Bushmeat hunting and use in the Makira Forest, north-eastern Madagascar: a conservation and livelihoods issue. Oryx 43:386-392

Goodman SM (1998) A floral and faunal inventory of the Réserve spéciale d'Anjanaharibe-Sud, Madagascar: with reference to elevational variation. In: Goodman SM (ed) A floral and faunal inventory of the Réserve spéciale d'Anjanaharibe-Sud, Madagascar: with reference to elevational variation. Field Museum of Natural History, Chicago, IL

Goodman SM (2012) Les carnivora de Madagascar. Association Vahatra, Antananarivo

Goodman SM, Helgen K (2010) Species limits and distribution of the Malagasy carnivoran genus Eupleres (Family Eupleridae). Mammalia 74:177-185

Goodman SM, Raherilalao MJ, Wohlhauser S (2018) The terrestrial protected areas of Madagascar: their history, description, and biota. Association Vahatra, Antananarivo

Hanley N, Spash C, Walker L (1995) Problems in valuing the benefits of biodiversity protection. Environ Resour Econ 5:249-272

Hawkins CE (1998) The behaviour and ecology of the fossa, Cryptoprocta ferox (Carnivora: Viverridae) in a dry deciduous forest in western Madagascar. PhD thesis, University of Aberdeen

* Hawkins CE, Racey PA (2005) Low population density of a tropical forest carnivore, Cryptoprocta ferox: implications for protected area management. Oryx 39:35-43

“ IUCN (2020) The IUCN Red List of Threatened Species, version 2020-1. https://www.iucnredlist.org (accessed 16 April 2020)

Jenkins RKB, Keane A, Rakotoarivelo AR, Rakotomboavonjy $\mathrm{V}$ and others (2011) Analysis of patterns of bushmeat consumption reveals extensive exploitation of protected species in eastern Madagascar. PLOS ONE 6:e27570

Koh LP, Lee TM, Sodhi NS, Ghazoul J (2010) An overhaul of the species-area approach for predicting biodiversity loss: incorporating matrix and edge effects. J Appl Ecol 47:1063-1070

Kotschwar-Logan M, Gerber BD, Karpanty SM, Justin S, Rabenahy FN (2015) Assessing carnivore distribution from local knowledge across a human-dominated landscape in central-southeastern Madagascar. Anim Conserv 18:82-91

Lenz BB, Jack KM, Spironello WR (2014) Edge effects in the primate community of the biological dynamics of forest fragments project, Amazonas, Brazil. Am J Phys Anthropol 155:436-446

Levin SA (ed) (2009) The Princeton guide to ecology. Princeton University Press, Princeton, NJ

MacKenzie DI, Nichols JD, Lachman GB, Droege S, Andrew Royle J, Langtimm CA (2002) Estimating site occupancy rates when detection probabilities are less than one. Ecology 83:2248-2255

Merson SD (2017) Bushmeat hunting, retaliatory killing, habitat degradation and exotic species as threats to fosa (Cryptoprocta ferox) conservation. PhD thesis, University of Oxford

Miller B, Dugelby B, Foreman D, del Rio CM and others (2001) The importance of large carnivores to healthy ecosystems. Endang Species Update 18:202-207

* Mittermeier RA, Myers N, Tliomsen JB, Olivieri S (1998) Biodiversity hotspots and major tropical wilderness areas: approaches to setting conservation priorities. Conserv Biol 12:516-520

* Morelli TL, Smith AB, Mancini AN, Balko EA and others (2020) The fate of Madagascar's rainforest habitat. Nat Clim Chang 10:89-96

Murphy AJ, Goodman SM, Farris ZJ, Karpanty SM, Andrianjakarivelo V, Kelly MJ (2017) Landscape trends in small mammal occupancy in the Makira-Masoala protected areas, northeastern Madagascar. J Mammal 98: 272-282

*Murphy AJ, Farris ZJ, Karpanty S, Kelly MJ and others (2018) Using camera traps to examine distribution and occupancy trends of ground-dwelling rainforest birds in north-eastern Madagascar. Bird Conserv Int 28:567-580

Myers N (1988) Threatened biotas: 'hot spots' in tropical forests. Environmentalist 8:187-208

Noss RF (1990) Indicators for monitoring biodiversity: a hierarchical approach. Conserv Biol 4:355-364

R Core Team (2014) R: a language and environment for statistical computing. R Foundation for Statistical Computing, Vienna

Rasambainarivo F, Farris ZJ, Andrianalizah H, Parker PG (2017) Interactions between carnivores in Madagascar and the risk of disease transmission. EcoHealth 14:691-703

Rasambainarivo F, Andriamihajarivo MN, Dubovi E, Parker PG (2018) Patterns of exposure of carnivores to selected pathogens in the Betampona Natural Reserve Landscape, Madagascar. J Wildl Dis 54:386-391

Thornton D, Zeller K, Rondinini C, Boitani L and others (2016) Assessing the umbrella value of a range-wide conservation network for jaguars (Panthera onca). Ecol Appl 26: 1112-1124

* Vieilledent G, Grinand C, Rakotomalala FA, Ranaivosoa R, Rakotoarijaona JR, Allnutt TF, Achard F (2018) Combining global tree cover loss data with historical national forest cover maps to look at six decades of deforestation and forest fragmentation in Madagascar. Biol Conserv 222:189-197 